\title{
THE EFFECT OF RELATIVE GROUP SIZE ON THE EMPLOYMENT PROSPECTS OF AFRICAN-AMERICAN AND WHITE MALES
}

\author{
Emily Hoffnar and Michael Greene*
}

\begin{abstract}
A bivariate probit model is employed to assess the impact of relative group size on employment and labor force participation probabilities of white and African-American males. The model allows for correlated error structures between labor force participation and employment equations. Increases in the relative size of the African-American population are found to have a significant negative impact on African-American male labor force participation and, after controlling for labor force participation, the probability of employment. No corresponding negative impact on white males is found.
\end{abstract}

This research note investigates (a) the impact of the relative size of the African-American population on male employment probabilities and (b) whether this effect is different for African-American than for white males. An examination of this issue is warranted for several reasons. First, a number of social scientists speculate that a group's relative size contributes to economic advancement by either providing the basis for entrepreneurial activity (Liberson, 1980; Drake and Clayton, 1962) or by creating the essential conditions for the accumulation of political bargaining power (Reich, 1971; Glenn, 1964). Secondly, increases in the relative size of a minority group may intensify competition over coveted resources and thereby trigger racial anxieties and animosities amongst the majority group; if large minority populations are perceived as a political and economic threat, the majority group may engage in activities repressing the advancement of the former (Brown and Fuguitt, 1972; Frisbie and Neidert, 1977; Tienda and Lii, 1987). Third, standard economic models of discrimination suggest that increases in the relative size of groups that are discriminated against may lead to decreases in their relative earnings status (Becker, 1971; Bergmann, 1974; Bellante, Kogut, and Moncarz, 1991). Finally, it is possible that increasing density exacerbates communication difficulties (Blalock, 1957), thereby hindering a group's ability to mobilize in pursuit of socioeconomic advancement. All of these reasons provide a compelling rationale for examining the impact of African-American density on the employment outcomes of white and African-American males. ${ }^{1}$

The remainder of this article is organized as follows. Section I develops the empirical methodology underlying this research and briefly discusses the data base employed. Section II presents and discusses the empirical results, while the final section summarizes the major findings.

\footnotetext{
*Assistant Professors, Department of Economics, University of North Texas, Denton, Texas.
} 


\section{EMPIRICAL MODEL AND DATA}

A bivariate probit model with correlated error structures is employed to estimate the effect of the relative size of the African-American population on the employment status of white and African-American males. The model includes both labor force participation and employment probability functions. This methodological approach is appealing because (a) joint estimation of the two equations provides substantial efficiency gains over that associated with separate estimation based on a two-stage technique, and (b) such estimation accounts for potential correlation between the employment and participation functions. In particular, maximization of the log-likelihood function produces a parameter, $\rho$, which mitigates against potential sample selectivity bias that might occur were the equations estimated separately (See Meng and Schmidt 1985; Boyes, Hoffman and Low, 1989). Indeed, models that neglect to account for the fact that employment status is only observed for those individuals who make the decision to enter the labor force (i.e., participate) are vulnerable to sample selectivity bias and as a result may generate misleading estimates of parameters (Reimers, 1983; Heckman, 1979). More formally, the model consists of (1) employment and (2) labor force participation equations:

$$
\begin{aligned}
& \operatorname{Prob}\left(\mathrm{EM}_{\mathrm{i}}\right)=\alpha_{1}+\beta_{1} \operatorname{PCTAA}_{\mathrm{i}}+\zeta_{1}\left(\operatorname{PCTAA}_{\mathrm{i}} * \mathrm{RACE}_{\mathrm{i}}\right)+\Sigma \delta_{\mathrm{j}} \mathrm{Z}_{\mathrm{ij}}+\epsilon_{\mathrm{i}} \\
& \operatorname{Prob}\left(\mathrm{LBF}_{\mathrm{i}}\right)=\alpha_{2}+\beta_{2} \operatorname{PCTAA}_{\mathrm{i}}+\zeta_{2}\left(\operatorname{PCTAA}_{\mathrm{i}} * \mathrm{RACE}_{\mathrm{i}}\right)+\Sigma \lambda_{\mathrm{j}} \mathrm{Z}_{\mathrm{ij}}+\varepsilon_{\mathrm{i}}
\end{aligned}
$$

For each individual (i), the probability of employment $\left(\operatorname{Prob}\left(\mathrm{EM}_{\mathrm{i}}\right)\right)$ and the probability of labor force participation $\left(\operatorname{Prob}\left(\operatorname{LFP}_{\mathrm{i}}\right)\right)$ depend on the percent of African Americans in the individual's MSA (PCTAA $A_{i}$ ); the individual's race $\left(\mathrm{RACE}_{\mathrm{i}}\right)$; and a vector of personal and local labor market controls $\left(\mathrm{Z}_{\mathrm{ij}}\right)$. All of the variables are defined in Table $1 . \epsilon_{\mathrm{i}}$ and $\varepsilon_{\mathrm{i}}$ are stochastic error terms within the employment and participation equations, respectively. Parameter estimates for $\alpha$, $\beta, \zeta$ and $\lambda$ are generated via joint estimation of (1) and (2) using the technique of full information maximum likelihood.

With regard to the primary research concern of this paper, we note that if the relative size of the African-American population lowers male employment probabilities, one would expect $\beta_{1}$ to be significantly negative. Such a finding would confirm that, ceteris paribus, employment prospects are lower for males residing in areas with a higher concentrations of African-Americans. The inclusion of the interaction term, $\left(\mathrm{PCTAA}_{\mathrm{i}}{ }^{*} \mathrm{RACE}_{\mathrm{i}}\right.$ ) permits an examination of whether, everything else being equal, relative size has a differential impact on the employment prospects of white and African-American males. If the effect of relative size dif- 
TABLE 1

Means and Variable Definitions

\begin{tabular}{llrr}
\hline Variable & \multicolumn{1}{c}{ Definition } & \multicolumn{2}{c}{ Means } \\
\cline { 3 - 4 } & & White & $\begin{array}{r}\text { African- } \\
\text { American }\end{array}$ \\
\hline EM & 1 if employed, else 0. & 0.849 & 0.723 \\
LBF & 1 if in labor force, else 0. & 0.908 & 0.820 \\
SCHOOL & Highest grade attended. & 13.683 & 12.352 \\
MARRIED & 1 if married, spouse present, else 0. & 0.625 & 0.429 \\
CHILDREN & Number of children in household & 0.722 & 0.807 \\
& $\quad$ under age 19 (truncated at 9). & & \\
PTIME & 1 if part time worker, else 0. & 0.141 & 0.259 \\
NE & 1 if household in Northeast, else 0. & 0.298 & 0.235 \\
MW & 1 if household in Midwest, else 0. & 0.260 & 0.231 \\
W & 1 if household in West, else 0. & 0.192 & 0.093 \\
URATE & Unemployment rate in MSA. & 6.14 & 6.04 \\
OTHER INCOME & Total family income less individual's & 20.820 & 16.262 \\
& $\quad$ earnings, in thousands. & & \\
AGE16TO24 & 1 if 16 to 24 years old, else 0. & 0.118 & 0.141 \\
AGE25TO34 & 1 if 25 to 34 years old, else 0. & 0.292 & 0.294 \\
AGE45TO54 & 1 if 45 to 54 years old, else 0. & 0.271 & 0.270 \\
AGE55TO64 & 1 if 55 to 64 years old, else 0. & 0.173 & 0.170 \\
RACE & 1 if African American, else 0. & 0.000 & 1.000 \\
PCTAA & Percent African-American in MSA. & 12.973 & 18.309 \\
\hline
\end{tabular}

fers by race, our bivariate probit model would show that $\zeta$ is significantly different from zero. Furthermore, if relative size translates into lower employment prospects for African-American males than for white males, then $\zeta_{1}$ will be negative and significant.

Data for this study are extracted from the 1990 Current Population Survey (CPS), March Annual Demographic File. We restrict coverage to white and African-American men between the ages of 16 and 64 who did not report themselves as being self-employed or in the military. Furthermore, we exclude all whites and African-Americans who identified their ethnic origin as "Hispanic"-as well as all "non-whites" who failed to identify themselves as "black." These restrictions result in a total sample size of 15,739. African-American men make up slightly more than 13 percent (2051) of the sample.

The explanatory variables in this study are as follows: years of education (SCHOOL), a dummy variable indicating whether the individual is "married, spouse present" (MARRIED), the number of children under the age of 19 in the household (CHILDREN), a binary variable indicating whether the individual reported "usually" working less than 35 hours per week (PTIME), three regional 
controls (Northeast, Midwest, and West; South is the reference group), the unemployment rate (URATE) of the Metropolitan Statistical Area (MSA) in which the individual reported residing, a measure of other family income (OTHER INCOME), four age-group dummy variables (AGE16-24, AGE25-34, AGE45-54, and AGE55-64; AGE35-44 is the omitted group), the percentage of the MSA population which is African-American (PCTAA), and an interaction between the individual's race and PCTAA. Similar variables are employed throughout the empirical literature on intergroup differences in labor market status; (e.g., Corcoran and Duncan, 1979; Carlson and Swartz,1988; Reimers, 1983; Stratton, 1993; Boyd, 1991; Lichter, 1988; Tienda and Lii, 1987). As a result, no attempt is made to justify their inclusion here. We do note, however, that an underlying assumption of this study is that employment status is best modelled as a function of both individual and labor market characteristics (Parcel, 1979). Our main focus, henceforth, is on the density (i.e., relative size) of the African-American population as the key independent variable of interest. This variable-as well as the MSA unemployment rate-is derived from the 1990 Census. Density measures were calculated for each MSA and subsequently matched to the MSA codes of the CPS.

\section{EMPIRICAL RESULTS}

Table 2 presents the bivariate probit coefficient estimates and slope estimates for the combined sample of white and African-American males. Column (2) presents the coefficient and slope estimates from the employment probability function, while column (3) contains the comparable results pertaining to the labor force participation function. Slope estimates are included because the coefficient estimates generated by the bivariate probit model cannot be interpreted as partial derivatives (slopes) of the employment and labor force participation functions. To obtain the slopes, each parameter estimate is multiplied by the bivariate normal density function, evaluated at the sample means. ${ }^{2}$ The slope associated with the variable SCHOOL in the employment function (.006), for example, indicates that an additional year of schooling results in an 0.6 percent increase in the probability of being employed. Each of the other slopes are interpreted in a similar fashion. ${ }^{3}$ Furthermore, we observe that the parameter $\rho$ provides an estimate of the correlation between the disturbance terms of the employment and participation functions. The estimated correlation is negative, but insignificant. A significant negative sign associated with this parameter would indicate that males who are more likely to participate in the labor force for unobservable reasons are less successful in securing employment once there. 
TABLE 2

Bivariate Probit Results

\begin{tabular}{|c|c|c|}
\hline & LOYMENT & LABOR FORCE PARTICIPATION \\
\hline CONSTANT & $\begin{array}{l}0.536 * * * \\
(0.138) \\
{[0.040]}\end{array}$ & $\begin{array}{l}1.298 * * * \\
(0.141) \\
{[0.096]}\end{array}$ \\
\hline SCHOOL & $\begin{array}{l}0.086 * * * \\
(0.007) \\
{[0.006]}\end{array}$ & $\begin{array}{l}0.075 * * * \\
(0.007) \\
{[0.006]}\end{array}$ \\
\hline MARRIED & $\begin{array}{l}0.284 * * * \\
(0.041) \\
{[0.021]}\end{array}$ & $\begin{array}{l}0.204 * * * \\
(0.048) \\
{[0.015]}\end{array}$ \\
\hline CHILDREN & $\begin{array}{c}0.015 \\
(0.018) \\
{[0.001]}\end{array}$ & $\begin{array}{c}-0.032 * \\
(0.019) \\
{[-0.002]}\end{array}$ \\
\hline PTIME & $\begin{array}{l}-0.456 * * * \\
(0.121) \\
{[-0.034]}\end{array}$ & $\begin{array}{l}-2.006 * * * \\
(0.039) \\
{[-0.149]}\end{array}$ \\
\hline NE & $\begin{array}{l}-0.204 * * * \\
(0.057) \\
{[-0.015]}\end{array}$ & $\begin{array}{l}0.004 \\
(0.061) \\
{[0.0003]}\end{array}$ \\
\hline MW & $\begin{array}{l}-0.188 * * * \\
(0.055) \\
{[-0.014]}\end{array}$ & $\begin{array}{l}0.131 * * \\
(0.061) \\
{[0.010]}\end{array}$ \\
\hline W & $\begin{array}{c}-0.027 \\
(0.067) \\
{[-0.002]}\end{array}$ & $\begin{array}{r}-0.017 \\
(0.074) \\
{[-0.001]}\end{array}$ \\
\hline URATE & $\begin{array}{l}-0.038 * * * \\
(0.015) \\
{[-0.003]}\end{array}$ & $\begin{array}{c}-0.022 \\
(0.016) \\
{[-0.002]}\end{array}$ \\
\hline OTHER INCOME & $\begin{array}{l}-0.002 * * * \\
(0.001) \\
{[-0.0002]}\end{array}$ & $\begin{array}{l}-0.004 * * * \\
(0.001) \\
{[-0.0003]}\end{array}$ \\
\hline AGE16TO24 & $\begin{array}{c}0.034 \\
(0.060) \\
{[0.003]}\end{array}$ & $\begin{array}{l}0.614 * * * \\
(0.067) \\
{[0.045]}\end{array}$ \\
\hline AGE25TO34 & $\begin{array}{c}0.032 \\
(0.045) \\
{[0.002]}\end{array}$ & $\begin{array}{l}0.129 * * \\
(0.061) \\
{[0.010]}\end{array}$ \\
\hline AGE45TO54 & $\begin{array}{c}0.079 \\
(0.055) \\
{[0.006]}\end{array}$ & $\begin{array}{l}-0.263 * * * \\
(0.070) \\
{[-0.019]}\end{array}$ \\
\hline
\end{tabular}


TABLE 2

Bivariate Probit Results (Continued)

\begin{tabular}{lcc}
\hline \hline & EMPLOYMENT & LABOR FORCE PARTICIPATION \\
\hline \multirow{2}{*}{ AGE55TO64 } & $0.267^{* * *}$ & $-0.976 * * *$ \\
& $(0.077)$ & $(0.063)$ \\
& {$[0.020]$} & {$[-0.072]$} \\
PCTAA & $0.006^{*}$ & 0.002 \\
& $(0.003)$ & $(0.003)$ \\
& {$[0.0004]$} & {$[0.0001]$} \\
RACE*PCTAA & $-0.011^{* * *}$ & $-0.010 * * *$ \\
& $(0.003)$ & $(0.003)$ \\
$\rho$ & {$[-0.001]$} & {$[-0.001]$} \\
& -0.182 & \\
\hline
\end{tabular}

***1 percent, ${ }^{* * 5}$ percent, ${ }^{*} 10$ percent significance level, 15739 observations standard errors in parentheses, partial derivatives evaluated at sample means in brackets

Empirical evidence generated by this research is strongly consistent with the hypothesis that the racial composition of the population has a different effect on the employment and labor force participation probabilities of white males than African-American males. The slopes associated with the variables PCTAA and (RACE*PCTAA) in the employment probability function, for instance, are .0004 and -.001 , respectively, indicating that a one percent increase in the relative size of the African-American population increases the employment probability of white males by .04 percent but reduces that of African-American men by .06 percent. ${ }^{4}$ Similarly, our results indicate that, ceteris paribus, while a one percent increase in the relative size of the African-American population has no statistically significant impact on the participation probability of white males, such an increase significantly lowers African-American male participation probability by .09 percent. Taken together, these findings (a) are inconsistent with those hypotheses suggesting that African-American density increases employment opportunities for African-American males and (b) indicate that the overall racial distribution of unemployment is influenced by the African-American proportion of the MSA population.

The bivariate probit coefficients associated with the remaining independent variables tend to have the expected signs and, with few exceptions, are found to be significantly different from zero. An additional year of schooling, for instance, increases both the probability of male employment and labor force participation by .6 percent. The string of dummy variables controlling for age groupings are significant in the participation function: compared to comparable men aged 35-44, 
men in the 16-24 and 25-34 age cohorts are more likely to enter the labor force, while those in the remaining cohorts (45-54 and 55-64) are significantly less likely to be labor force participants. In effect, these patterns assume the shape of an inverted $U$ and reflect the fact that male labor force participation rates begin to significantly decline after the age of 45 , with the drop being particularly dramatic among the oldest group. After controlling for labor force participation however, age is found to have little impact on employment. Only older workers (those from 55 to 64 years of age) stand out as significantly different from prime age (35 to 44 years of age) males. This cohort is approximately 2 percent more likely than those aged 35-44 to be employed, all else being equal.

Other major determinants of male employment-participation probabilities include other income, MSA unemployment rate, marital status, and the number of children within the household. The signs associated with each of these variables are generally consistent with labor market theories regarding search and labor force participation (Devine and Kiefer, 1991). In particular, search theory suggests that a person chooses to be in the labor force when the expected benefits of search exceed the costs. We find, for instance, a significantly negative relationship between the local unemployment rate and the probability of employment-a finding similar to that reported by Stratton (1993) and consistent with the hypothesis that, among those who enter the labor force, the search process is more likely to be fruitful (less costly) in areas characterized by low rather than high unemployment rates.

Search theory also implies that, everything else being equal, there is an inverse relationship between the reservation wage (i.e., the lowest wage sufficient to induce individuals to enter the labor market and accept employment offers) and employment-participation probabilities. Males with less other family income to rely upon, for instance, are likely to have lower reservation wages and hence should evidence greater probabilities of entering the labor force, as well as an increased likelihood of accepting job offers. Indeed, the variable OTHER INCOME is significantly negative in both our employment and participation functions, suggesting that a $\$ 1,000$ decrease in other family income increases the probabilities of employment and participation by approximately .02 percent and .03 percent, respectively.

To the extent that marriage increases the need for male income, thus decreasing the reservation wage, the positive coefficients in both employment and participation equations are not surprising. We find that being "married, spouse present" increases the participation and employment probabilities by approximately 1.5 percent and 2.1 percent, respectively. ${ }^{5}$ The number of children, on the other hand, is found to be negatively related to the probability of labor force participation. One explanation of the negative sign associated with the vari- 
able CHILDREN is that men living with children place a greater value on their leisure time (i.e., non-market time) and hence have higher reservation wages than comparable men not living with children. It is worthwhile noting, however, that the presence of children can also operate in the opposite direction-namely, increasing the need for income and thereby lowering the reservation wage. For the males in our sample, our results suggest that this latter may be outweighed by the former effect.

Finally, this research suggests that male employment opportunities are greater within the South than elsewhere in the nation. Of the three regional controls in the employment probability function, two are found to have significantly negative signs. Compared to southern males, those residing in the North-East and Mid-West are approximately 1.5 percent and 1.4 percent, respectively, less likely to be employed. These results are consistent with the hypothesis that shifting of employment opportunities from the Snowbelt to the Sunbelt has dampened the employment prospects of males residing outside of the South. Interestingly, we find no evidence that males residing in the Northeast and Midwest are less likely than those living in the South to participate in the labor force; the coefficient associated with the Northeast is insignificant, while that for men residing in the Midwest is both positive and significant, with a slope estimate implying that males within this region are about 1 percent more likely than their southern counterparts to be labor force participants. The primary effect of southern residence, however, appears to be increasing employment probabilities, particularly in comparison to those probabilities in the Northeast and Midwest.

\section{CONCLUSIONS}

This research has examined the impact of the relative size of the AfricanAmerican population on employment and labor force participation probabilities of white and African-American males. Using a bivariate probit model to jointly assess the determinants of participation and employment probabilities-and to mitigate against potential sample selectivity bias-we find that increases in African-American density (a) have no appreciable effect on the labor force participation probability of white males, but significantly lower the likelihood for African-American men; and (b) after controlling for labor force participation, increases in African-American density reduce the employment probability of African-American men. A number of implications emerge from these findings.

First, and perhaps most importantly, evidence generated by this research is inconsistent with those hypotheses maintaining that group density is positively related to African-American economic status. Were this the case, one would expect 
increases in the relative size of the African-American population within an MSA to increase rather than decrease African-American participation and employment probabilities. To the extent that increases in employment and participation probabilities are reliable indicators of improved economic wellbeing, the empirical evidence reported here suggests that increases in relative size significantly worsens the economic status of African-American males.

Secondly, the distribution of overall MSA unemployment is influenced by the relative size of the African-American population. We find that the percentage of the MSA population that is African-American increases white male employment probabilities. This is unsurprising, given the fact that we control for MSA unemployment rates in our model. Thus, given a constant unemployment rate, an increase in the probability of African-American unemployment, ceteris paribus, implies an decrease in the probability of white unemployment.

Finally, our results indicate the importance of continuing research in a number of areas related to the impact of group density on participation-employment probabilities. Among these are the questions: Does relative group size have the same effect on the participation-employment outcomes of women as for males? Does the impact of group density systematically vary across regions (e.g., is the effect of African-American density on labor market outcomes different for southern than non-southern residents?). What impact, if any, do increases in the relative size of other ethnic/racial groups (e.g., Hispanics) have on AfricanAmerican employment probabilities? Has the importance of African-American density changed over the last few decades, and, if so, in what direction? Such areas of inquiry, we believe, are part of a growing and important genre of research on intergroup differences in socioeconomic status.

\section{ENDNOTES}

1. The research reported here is part of a more general literature dealing with the relationship between spatial concentration and economic status, (e.g., Kain 1968; Mooney 1969; Masters 1974; Danziger and Weinstein 1976; Straszheim 1980; Price and Mills 1985; and Sexton 1991). Earlier attempts to measure the relationship between spatial concentration and economic status tended to (a) focus on employment outcomes, e.g., Kain (1968) and (b) employed several different measures to capture the degree of spatial isolation, including distance of worksites from the nearest ghetto (Kain, 1968), indexes of residential segregation (Masters, 1974), and central city versus suburban residence (Price and Mills, 1985; Danziger and Weinstein, 1976). Similar to this genre of research, our work is focused on the spatial dimension of intergroup differences in economic 
status, although our measure of the spatial dimension is somewhat differentnamely, the percentage of the Metropolitan Statistical Area (MSA) which is African-American. Moreover-and as described in the text-our use of a bivariate probit model permits us to jointly examine the impact of density on both labor force participation and employment outcomes.

2. We follow Allen et al. (1993) in reporting coefficient estimates and corresponding slope estimates. Standard errors refer to coefficient estimates.

3. The slopes reported for the dummy variables are not true partial derivatives, but closely approximate the change in the cumulative distribution function (evaluated at the sample means) when the relevant dummy variable is changed from zero to one. See Greene (1993), page 641.

4. The effect of PCTAA on African American males is obtained by adding the coefficients associated with PCTAA and (RACE*PCTAA).

5. Korenman and Neumark (1991) also find that, ceteris paribus, the hourly wage of married males is about 10 percent higher than that of comparably skilled single males. This suggests that married males are more likely to confront wage offers that exceed their reservation wage. Hence, one would expect them to be more likely to enter the labor force and accept employment.

\section{REFERENCES}

Allen, Steven G., Robert L. Clark and Ann A. McDermed. "Pensions, Bonding, and Lifetime Jobs." Journal of Human Resources 28 (1993): 463-481.

Becker, Gary S. The Economics of Discrimination. Chicago, IL: University of Chicago Press, 1971.

Bellante, Don, Carl A. Kogut and Raul Moncarz. "Hispanics and the Local Labour Market Earnings of Blacks." International Journal of Manpower 12 (1991): 22-26.

Bergmann, Barbara. "Occupational Segregation, Wages and Profits When Employers Discriminate by Race or Sex." Eastern Economic Journal 1 (1974): 103-110.

Blalock, Hubert M., Jr. "Percent Nonwhite and Discrimination In the South." American Sociological Review 22 (1957): 677-682.

Boyd, Robert L. "Effects of Relative Group Size, Increase, and Segregation on the Earnings of Blacks and Asians." Sociological Focus 24 (1991): 175-183.

Boyes, William J., Dennis L. Hoffman, and Stuart Low. "An Econometric Analysis of the Bank Credit Scoring Problem." Journal of Econometrics 40 (1989): 3-14. 
Brown, D.L., and Glenn V. Fuguitt. "Percent Nonwhite and Racial Disparity in Nonmetropolitan Cities in the South." Social Science Quarterly 54 (1972): 573-582.

Carlson, Leonard A., and Caroline Swartz. "The Earnings of Women and Ethnic Minorities, 1959-1979." Industrial and Labor Relations Review 41 (1988): 530-545.

Corcoran, Mary and Gregory Duncan. "Work History, Labor Force Attachment and Earnings Differences between the Races and Sexes." Journal of Human Resources 14 (1979): 5-19.

Daniziger, Sheldon, and Michael Weinstein. "Employment Location and Wage Rates of Poverty-Area Residents." Journal of Urban Economics 3 (1976): 127-145.

Devine, Theresa J., and Nicholas M. Kiefer. Empirical Labor Economics: The Search Approach. New York, NY: Oxford University Press, Inc., 1991.

Drake, St. Clair, and Horace R. Clayton. Black Metropolis. New York, NY: Harper Books, 1962.

Frisbe, W. Parker, and Lisa Neidert. "Inequality and the Relative Size of Minority Populations: A Comparative Analysis." American Journal of Sociology 82 (1977): 1007-1030.

Glenn, Norval D. "The Relative Size of the Negro Population and Negro Occupational Status." Social Forces 43 (1964): 42-49.

Greene, William H. Econometric Analysis. Second Edition. New York, NY: Macmillan Publishing Company, 1993.

Heckman, James. "Sample Selection Bias as a Specification Error." Econometrica 47 (1979): 153-161.

Kain, John F. "Housing Segregation, Negro Employment, and Metropolitan Decentralization." Quarterly Journal of Economics 82 (1968): 175-197.

Korenman and Neumark. "Does Marriage Really Make Men More Productive?" Journal of Human Resources 26 (1991): 282-307.

Liberson, Stanley. A Piece of the Pie: Black and White Immigrants Since 1880. Berkeley, CA: University of California Press, 1980.

Lichter, Daniel T. "Racial Differences In Underemployment in American Cities." American Journal of Sociology 93 (1988): 771-792.

Masters, Stanley H. "A Note on John Kain's 'Housing Segregation, Negro Employment, and Metropolitan Decentralization'." Quarterly Journal of Economics 88 (1974): 505-512.

Meng, C.L., and P. Schmidt. "On the Cost of Partial Observability in the Bivariate Probit Model." International Economic Review 26 (1985): 71-85. 
Mooney, Joseph D. "Housing Segregation, Negro Employment and Metropolitan Desegregation: An Alternative Perspective." Quarterly Journal of Economics 83 (1969): 299-311.

Parcel, Toby L. "Race, Regional Labor Markets, and Earnings." American Sociological Review 44 (1979): 262-279.

Price, Richard, and Edwin Mills. "Race and Residence in Earnings Determination." Journal of Urban Economics 18 (1985): 350-363.

Reich, Michael. "The Economics of Racism." 107-113. In D. M. Gordon (ed.). Problems In Political Economy: An Urban Perspective. Lexington, Mass.: Heath Books, 1971.

Reimers, Cordelia. "Labor Market Discrimination Against Hispanic and Black Men." Review of Economics and Statistics 65 (1983): 570-579.

Sexton, Edwin A. "Residential Location, Workplace Location, and Black Earnings." Review of Regional Studies 17 (1991): 11-20.

Straszheim, Mahlon R. "Discrimination and the Spatial Characteristics of the Urban Labor Market for Black Workers." Journal of Urban Economics 7 (1980): 119-140.

Stratton, Leslie S. "Racial Differences In Men's Unemployment." Industrial and Labor Relations Review 46 (1993): 461-464.

Tienda, Marta, and Ding-Tzann Lii. "Minority Concentration and Earnings: Blacks, Hispanics, and Asians Compared." American Journal of Sociology 93 (1987): 141-165.

U.S. Department of Commerce, Bureau of the Census. Current Population Survey: Annual Demographic File, 1990 [Computer file]. 2nd release. Washington, DC: U.S. Department of Commerce, Bureau of the Census [producer], 1991. Ann Arbor, MI: Inter-university Consortium for Political and Social Research, [distributor], 1991.

U.S. Department of Commerce. Bureau of the Census. Census of Housing and Population, 1990, 1993. 